\title{
Pengaruh Latihan 3 Cone Wall Passing dan "V" Roll To Gated Pass Terhadap Akurasi Passing Bawah
}

\author{
Noor Akhmad, Adi Suriatno \\ Program Studi Pendidikan Olahraga dan Kesehatan, Fakultas Ilmu Keolahragaan dan \\ Kesehatan Masyarakat, Universitas Pendidikan Mandalika \\ noorakhmad889@yahoo.com
}

Received: Januari 2021; Accepted: Februari 2021; Published: Maret 2021

Ed: Maret 2021; 8(1): 29-36

\begin{abstract}
Abstrak
Sepak bola juga merupakan salah satu cabang olahraga yang ada di Provinsi Nusa Tenggara Barat yang sangat di gemari di kalangan masyarakat. Prestasi tertinggi yang pernah di torehkan oleh cabang olahraga Sepak Bola Nusa Tenggara Barat adalah ikut serta ajang Pekan Olahraga Nasional (PON) Riau tahun 2012. Tujuan penelitian untuk mengetahui Pengaruh Latihan 3 Cone Wall Passing Dan "V" roll to gated pass Terhadap Akurasi Passing Bawah Pemain SSB Neo Selaparang KU 12 Tahun 2021. Penelitian ini menggunakan metode Experimental Design dengan model one-group pretest-postest design. Populasi dalam penelitian ini dipasangkan (matched) dengan pola A-B-B-A dalam dua kelompok dengan anggota masing-masing 10 atlet berjumlah 20 pemain. Teknik pembagian sampel menggunakan ordinal pairing. Instrumen dalam penelitian ini tes keterampilan dasar bermain sepak bola. Analisis data penelitan ini menggunakan uji-t. Hasil penelitian menunjukkan bahwa: kelompok latihan 3 cone wall passing didapatkan hasil t hitung 6,167, kelompok latihan " $V$ " roll to gated pass $\mathrm{t}$ hitung 4,311 dan t tabel (df 11) 2,201 “ Kesimpulan penelitian ini adalah Ada pengaruh yang signifikan latihan 3 cone wall passing terhadap akurasi passing pemain SSB Neo Selaparang KU 12 tahun dan Ada pengaruh yang signifikan latihan " $V$ " roll to gated pass terhadap akurasi passing bawah pemain SSB Neo Selaparang KU 12 tahun.
\end{abstract}

Kata Kunci: Latihan 3 Cone Wall Passing, "V" roll to gated pass, Pasing Sepak Bola.

\begin{abstract}
Football is also one of the sports in West Nusa Tenggara Province which is very popular among the people. The highest achievement ever inscribed by the West Nusa Tenggara Football sport was participating in the Riau National Sports Week (PON) in 2012. The purpose of the study was to determine the effect of 3 Cone Wall Passing and " $V$ " Roll To Gated Pass Exercises on Bottom Passing Accuracy. SSB Neo Selaparang KU 12 Players in 2021. This research uses the Experimental Design method with a one-group pretest-posttest design model. The population in this study was matched with the A-B-B-A pattern in two groups with 10 athletes each consisting of 20 players. The sampling technique used is ordinal pairing. The instrument in this study was a test of basic soccer skills. The data analysis of this research used $t$-test. The results showed that: the 3 cone wall passing exercise group obtained tcount 6,167 , the " $V$ " roll to gated pass exercise group $t$ calculated 4,311 and t table (df 11) 2,201 "The conclusion of this study is that there is a significant effect of 3 cone wall exercises passing on the passing accuracy of the 12-year-old SSB Neo Selaparang KU player and There is a significant effect of the " $V$ " roll to gated pass exercise on the accuracy of the underhand passing of the 12-year-old SSB Neo Selaparang KU player.
\end{abstract}

Keywords: Practice 3 Cone Wall Passing, "V" roll to gated pass, Soccer Passing.

\section{PENDAHULUAN}

Olahraga merupakan segala aktifitas fisik yang di lakukan dengan sengaja dan sistematis untuk mendorong, membina dan mengembangkan potensi jasmani, rhani dan soisal. Suatu kegiatan 
jasmani yang di lakukan dengan maksud untuk memelihara kesehatan dan memperkuat otot-otot tubuh.Kegiatan ini dalam perkembangannya dapat di lakukan sebagai kegiatan yang menghibur, menyenangkan atau juga di lakukan dengan tujuan untuk meningkatkan prestasi. Sepak bola merupakan olahraga yang paling populer di dunia. Di Indonesia banyak terdapat klub-klub sepakbola dari klub amatir yang berkompetisi dari tingkat Pengcab (Pengurus Cabang) PSSI (Persatuan Sepakbola Seluruh Indonesia), Divisi III, Divisi II dan Divisi I PSSI Pusat sampai klub Non Amatir yang berkompetisi ditingkat divisi utama dan Liga Super Indonesia (Primasoni \& Sulistiyono, 2010: 93). Sepakbola adalah salah satu permainan bola besar yang beranggotakan sebelas pemain yang bertujuan untuk mencetak gol ke gawang lawan dengan cara memasukkan bola ke gawang lawan. Permainan ini, teknik atau kemampuan dasar bermain sepakbola sangat berpengaruh terhadap kualitas permainan seseorang, dikarenakan hal tersebut merupakan salah satu modal utama dalam bermain sepak bola.Sepak bola juga merupakan salah satu cabang olahragayang ada di Provinsi Nusa Tenggara Barat yang sangat di gemari di kalangan masyarakat. Prestasi tertinggi yang pernah di torehkan oleh cabang olahraga sepak bola Nusa Tenggara Barat adalah ikut serta ajang Pekan Olahraga Nasional(PON) Riau tahun 2012 silam, selain itu di Nusa Tenggara Barat terdapat sepak bola Liga 2 yaitu PS Sumbawa Barat. Permainan sepakbola merupakan cabang olahraga permainan beregu atau permainan tim, maka suatu kesebelasan yang baik, kuat, dan tangguh adalah kesebelasan yang mampu menyelenggarakan permainan secara kompak, artinya memunyai kerja sama tim yang baik dan tangguh. Seperti yang diungkapkan Taga \& Asai (2011: 35) bahwa "Soccer requires a combination of technique, tactics, physical fitness, mental strength, and teamwork".

Bompa (1994: 51), bahwa pelatihan yang diberikan secara teratur selama 6-8 minggu akan mendapatkan hasil tertentu dimana tubuh teradaptasi dengan pelatihan yang diberikan. Selanjutnya Nala (2011: 37), menyatakan bahwa pelatihan yang diberikan secara sistematis, progresif dan berulang-ulang akan memperbaiki sistem organ tubuh sehingga penampilan fisik akan optimal. Pelatihan yang dilakukan dengan frekuensi tiga kali seminggu, sesuai untuk para pemula akan menghasilkan peningkatan yang berarti. Gerakan yang dilakukan saat latihan dengan cara berulang-ulang akan menyebabkan terjadinya pembentukan refleks bersyarat, belajar bergerak, dan proses penghafalan gerak (Nala, 2011:39). Gerak yang terjadi dalam aktivitas olahraga, merupakan akibat adanya stimulus yang diproses di dalam otak dan selanjutnya direspon melalui kontraksi otot, setelah menerima perintah dari sistem komando syaraf, yaitu otak. Oleh karena itu keterampilan gerak selalu berhubungan dengan sistem motorik internal tubuh manusia yang hasilnya dapat diamati sebagai perubahan posisi sebagian badan atau anggota badan (Schmidt \& Lee, 2008: 334). Belajar gerak merupakan suatu rangkaian asosiasi latihan atau pengalaman yang dapat mengubah kemampuan gerak ke arah kinerja keterampilan gerak tertentu. Sehubungan dengan hal tersebut, perubahan keterampilan gerak dalam belajar gerak merupakan indikasi terjadinya proses belajar gerak yang dilakukan oleh seseorang.

Dengan demikian, keterampilan gerak yang diperoleh bukan hanya dipengaruhi oleh faktor kematangan gerak melainkan juga oleh faktor proses belajar gerak. Selanjutnya gerak yang dilakukan secara berulang-ulang akan tersimpan dalam memori pelaku yang sewaktu-waktu akan muncul bila ada stimulus yang sama. Untuk itu, keterampilan gerak dalam olahraga harus selalu dilatihkan secara berulang-ulang agar tidak mudah hilang dari memori, sehingga individu tetap terampil dalam setiap melakukan gerakan. Peningkatan kemampuan yang terjadi dikarenakan adanya asosiasi pengetahuan yang diperoleh anak pada pertemuan sebelumnya dengan pengetahuan yang baru dan asosiasi tersebut semakin kuat ketika dilakukan secara berulang. Hal ini berdasarkan pada teori belajar law of exercise yang dikemukakan oleh Rahyubi (2012: 164) 
yang menyatakan bahwa "prinsip hukum latihan menunjukkan bahwa prinsip utama dalam belajar adalah pengulangan, semakin sering diulangi materi pelajaran akan semakin dikuasai”.

Teknik dasar bermain sepakbola merupakan semua gerakan yang diperlukan untuk bermain sepakbola, dan untuk dapat bermain sepakboladengan baik, seorang pemain perlu meningkatkan keterampilan teknik dasar sepakbola tersebut. Permainan sepak bola merupakan permainan yang dilaksanakan selain mengandalkan tehnik individu, juga merupakan permainan yang lebih mengandalkan keutuhan sebuah tim yang baik (Yanuar \& Andi, 2020). Teknik dasar bermain sepakbola meliputi teknik tanpa bola dan teknik dengan bola. Subroto (2009: 85) menyatakan teknik dasar sepakbola terdiri atas: (1) teknik tanpa bola, meliputi lari cepat dan mengubah arah, melompat/meloncat, gerak tipu tanpa bola, gerakan-gerakan khusus penjaga gawang, dan (2) teknik dengan bola meliputi mengenal bola, menendang, menerima/mengontrol bola, menggiring, menyundul, melempar bola, gerak tipu dengan bola, merebut bola, dan teknik-teknik khusus penjagagawang. Dalam latihan ini peneliti membuat beberapa bentuk variasi latihan " $V$ " roll to gated pass agar para pemain tidak mengalami kejenuhan dalam berlatih. Permasalahan yang telah dikemukakan di atas melatar belakangi peneliti untuk melakukan penelitian yang berjudul "Pengaruh Latihan 3 cone wall passing dan " $V$ " roll to gated pass terhadap Akurasi Passing Bawah Pemain SSB Neo Selaparang KU 12 Tahun 2020".

\section{METODE}

Jenis penelitian ini adalah eksperimen. Metode eksperimen Metode Eksperimen adalah metode penelitian yang bertujuan untuk menjelaskan hubungan sebab-akibat (kausalitas) antara satu variabel dengan lainnya (variabel X dan variabel Y) (Siyoto \& Sodik, 2015: 22). Desain yang digunakan dalam penelitian ini adalah "Two Groups Pretest-Posttest Design", yaitu desain penelitian yang terdapat pretest sebelum diberi perlakuan dan posttest setelah diberi perlakuan, dengan demikian dapat diketahui lebih akurat, karena dapat membandingkan dengan diadakan sebelum diberi perlakuan (Sugiyono, 2007: 64). Adapun rancangan tersebut dapat digambarkan sebagai berikut:

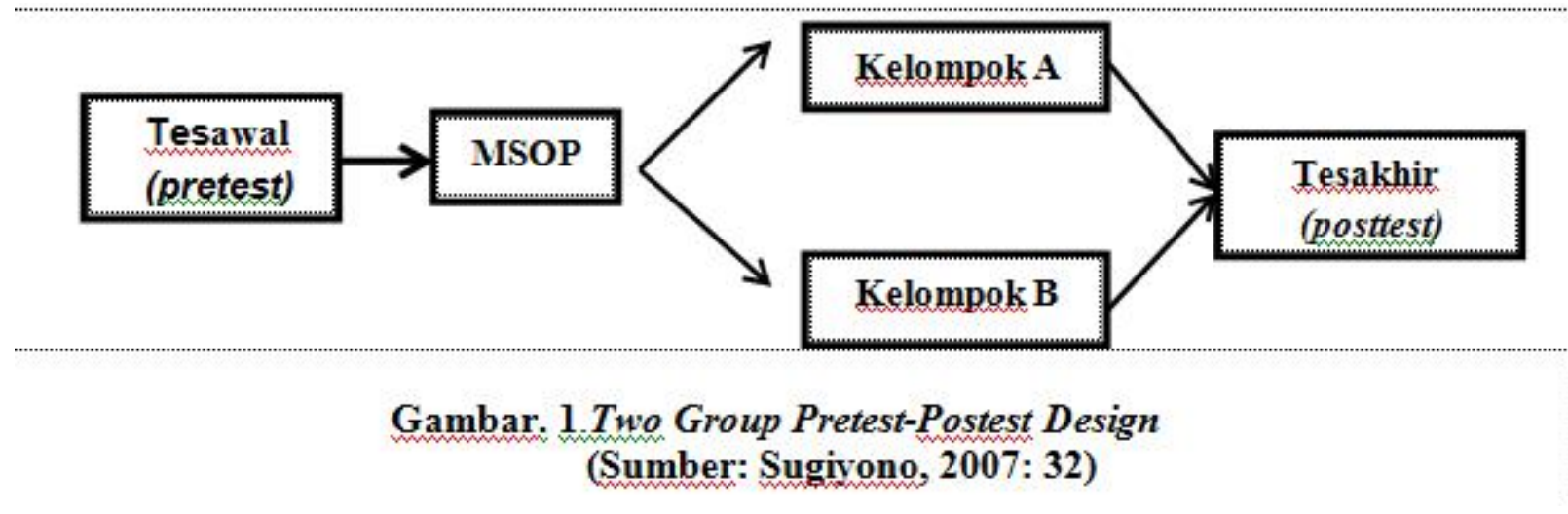

Keterangan:

$\begin{array}{lll}\text { Pre-test } & : & \text { Tes awal ketepatan passing } \\ \text { MSOP } & : & \text { Matched Subject Ordinal Pairing (pasangan ordinal subjek yang cocok) } \\ \text { Kelompok A } & : & \text { Perlakuan (treatment) } 3 \text { cone wall passing } \\ \text { Kelompok B } & : & \text { Perlakuan (treatment) "V" roll to gated pass } \\ \text { Post-test } & : & \text { Tes akhir ketepatan passing }\end{array}$


Siyoto \& Sodik (2015: 64) menyatakan bahwa: Sampel adalah sebagian dari jumlah dan karakteristik yang dimiliki oleh populasi tersebut,ataupun bagian kecil dari anggota populasi yang diambil menurut prosedur tertentu, sehingga dapat mewakili populasinya. Pengambilan sampel dalam penelitian ini dilakukan dengan puposive sampling. Siyoto \& Sodik (2015: 66)"menyatakan purposive sampling adalah suatu teknik penentuan sampel dengan pertimbangan tertentu ataus eleksikhusus". Kriteria dalam penentuan sampel meliputi:(1) pemain berusia 12tahun,(2) tidak dalam keadaan sakit,(3) Kehadiran pada saat treatment minimal 75\%, (4) Sanggup mengikuti seluruh program latihan yang telah disusun. Berdasarkan kriteria tersebut yang memenuhi berjumlah 20 pemain. Seluruh sampel tersebut dikenai pretest ketepatan passing untuk menentukan kelompok treatment, pola A-B-B-A dalam dua kelompok dengan anggota masing-masing 10 atlet. Teknik pembagian sampel menggunakan ordinal pairing.Sampel dibagi menjadi dua kelompok, Kelompo A diberi latihan 3 cone wall passing dan kelompok B diberi latihan " $V$ " roll to gated pass. Hasil pengelompokkan berdasarkan ordinal pairing adalah sebagai berikut:

Tabel. 1.Teknik Pembagian Sampel dengan Ordinal Pairing

\begin{tabular}{|c|c|}
\hline Kelompok A & Kelompok B \\
\hline 1 & 2 \\
\hline 4 & 3 \\
\hline 5 & 6 \\
\hline Dst & 7 \\
\hline
\end{tabular}

Tempat penelitian yaitu di SSB Neo Selaparang Mataram Pemberian perlakuan (treatment) dilaksanakan sebanyak 16 kali pertemuan, dengan frekuensi 3 kali dalam satu minggu, yaitu hari Selasa, Jumat, dan Minggu.

Instrumen tes yang digunakan untuk pengukuran awal (pretest) maupun pengukuran akhir (posttest) menggunakan tes keterampilan bermain sepakbola yang disusun oleh Irianto (1995: 9) pada bagian "melakukan passing rendah menuju sasaran", yaitu gawang kecil yang berbentuk bidang yang menjadi sasaran dengan ukuran lebar $1,5 \mathrm{~m}$ dan tinggi pancang $0,5 \mathrm{~m}$ dengan jarak penendang dari gawang $9 \mathrm{~m}$ dan garis di belakang gawang juga $9 \mathrm{~m}$ dan garis batas sah $1,5 \mathrm{~m}$. Validitas tes tersebut adalah 0,812 dan reliabilitas sebesar 0,856 .

Passing dikatakan tepat apabila masuk pada sasaran yang telah ditentukan melewati garis sah yang telah ditentukan. Tes ini dimaksudkan untuk mengukur ketepatan passing bawah menggunakan kaki bagian dalam.Pengumpulan data pada penelitian ini menggunakan tes dan pengukuran. Alat yang digunakan adalah gawang kecil dengan ukuran lebar 1,5 $\mathrm{m}$ dan tinggi 0,5 $\mathrm{m}$ dengan jarak penendang dari gawang $9 \mathrm{~m}$, garis di belakang gawang juga $9 \mathrm{~m}$, dan garis sah panjanganya $1,5 \mathrm{~m}$. Tendangan sah dan dianggap masuk apabila masuk pada bidang bidang sasaran, mengenai batas atas dan atau mengenai pancang, dan kerasnya tendangan harus sampai pada garis batas belakang gawang (jarak $9 \mathrm{~m}$ ). Penilaian adalah jumlah tendangan yang masuk sah dari sepuluh kali tendangan. 


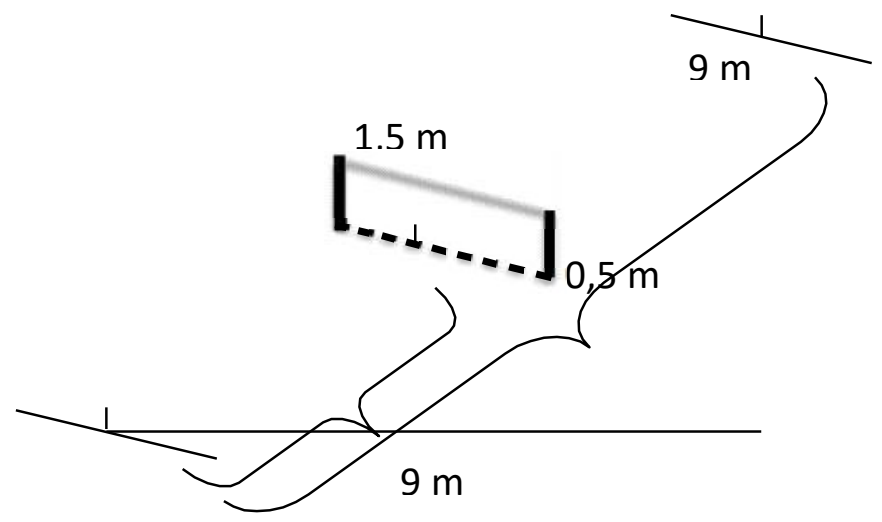

Gambar 2. Tes Mengoper Bola Rendah/Pendek (Sumber: Irianto, 1995: 34)

Sebelum dilakukan pengujian hipotesis, maka perlu dilakukan uji prasyarat. Pengujian data hasil pengukuran yang berhubungan dengan hasil penelitian bertujuan untuk membantu analisis agar menjadi lebih baik. Sebelum melangkah keuji-t , ada persyaratan yang harus dipenuhi oleh peneliti bahwa data yang dianalisis harus berdistribusi normal, untuk itu perlu dilakukan uji normalitas dan uji homogenitas (Arikunto, 2006: 299). Analisis data mengunakan dengan bantuan program SPSS 16, apabila nilai $\mathrm{t}$ hitung lebih kecil dari $\mathrm{t}$ tabel, maka Ha ditolak, jika $\mathrm{t}$ hitung lebih besar dibanding t tabel dan nilai sig $\mathrm{p}<0,05$, maka Ha diterima.

\section{HASIL DAN PEMBAHASAN}

1. Hasil Pretest dan Posttest Akurasi Passing pada Pemain SSB Neo Selaparang KU 12 Tahun Kelompok Latihan 3 Cone Wall Passing (A).

Tabel. 2.Hasil Pre-Test dan Post Test Akurasi Passing pada Pemain SSB Neo Selaparang KU 12 Tahun Kelompok Latihan 3 Cone Wall Passing (A).

\begin{tabular}{|c|r|r|r|r|r|r|}
\hline Kelompok & \multirow{2}{*}{ Rata-rata } & \multicolumn{4}{|c|}{ t-test for Equality of means } \\
\cline { 5 - 7 } & & $\mathbf{t ~ h t}$ & $\mathbf{t ~ t b}$ & Sig. & Selisih & \% \\
\hline Pretest & 3.08 & 6,167 & 2,201 & 0,000 & 1,833 & $59,51 \%$ \\
\hline Posttest & 4.92 & & & & & \\
\hline
\end{tabular}

Dari hasil perhitungan di dapatkan nilai Sig. 0,000, oleh karena penelitian dinyatakan signifikan jika nilai $t$ hitung $>\mathrm{t}$ tabel atau nilai sig lebih kecil dari 0.05 (Sig < 0.05). "Ada pengaruh yang signifikan latihan 3 cone wall passing terhadap akurasi passing pemain SSB Neo Selaparang KU 12 tahun",diterima. 


\section{Hasil Pretest Dan Posttest Akurasi Passing Pada Pemain SSB Neo Selaparang KU 12 Tahun Kelompok Latihan " $V$ ” roll to gated pass (B).}

Tabel. 3. Hasil Pre-Test dan Post Test Akurasi Passing pada Pemain SSB Neo Selaparang KU 12 Tahun Kelompok Latihan 3 Cone Wall Passing (A).

\begin{tabular}{|c|r|r|r|r|r|c|}
\hline Kelompok & Rata-rata & \multicolumn{5}{|c|}{ t-test for Equality of means } \\
\cline { 3 - 6 } & & $\mathbf{t ~ h t}$ & $\mathbf{t ~ t b}$ & Sig. & Selisih & \% \\
\hline Pretest & 3.17 & 4,311 & 2,201 & 0,001 & 1,167 & $36,81 \%$ \\
\hline Posttest & 4.33 & & & & & \\
\hline
\end{tabular}

Dari hasil perhitungan di dapatkan nilai Sig. 0,001, oleh karena penelitian dinyatakan signifikan jika nilai t hitung $>\mathrm{t}$ tabel atau nilai sig lebih kecil dari 0.05 (Sig < 0.05). Ada pengaruh yang signifikan latihan " $V$ " roll to gated pass terhadap akurasi passing bawah pemain SSB Neo Selaparang KU 12 tahun”, diterima.

\section{PEMBAHASAN}

Berdasarkan analisis uji t yang dilakukan maka dapat diketahui beberapa hal untuk mengambil kesimpulan apakah ada peningkatan akurasi passing pemain SSB Neo Selaparang KU 12 tahun setelah mengikuti metode latihan " 3 cone wall passing" dan " $V$ " roll to gated pass selama 16 kali pertemuan. Hasil penelitian dibahas secara rinci sebagai berikut:

\section{Pengaruh Metode Latihan 3 Cone Wall Passing Terhadap Akurasi Passing}

Berdasarkan hasil penelitian menunjukkan bahwa ada pengaruh yang signifikan latihan 3 cone wall passing terhadap akurasi passing pemain SSB Neo Selaparang KU 12 tahun, dengan kenaikan persentase sebesar 59,51\%. Latihan 3 cone wall passing adalah bentuk latihan passing yang sangat mudah untuk dilakukan oleh pemain usia dini terutama usia 12 tahun dan merupakan latihan yang efektif dalam meningkatkan akurasi dan kontrol pemain. Bentuk latihan ini yaitu tersusun dari 3 cone yang dijajarkan dan divariasikan dengan di depan 3 cone dengan jarak 10-20 meter terdapat target gawang kecil yang tersusun oleh 2 cone. Kemudian pemain mendribbling ke kanan dan ke kiri lalu passing ke target.Latihan ini dilakukan untuk meningkatkan kemampuan ketepatan passing sekaligus untuk meningkatkan kemampuan kontrol bola dari pemain yang melakukannya. Akan tetapi model latihan ini kurang baik karena anak latih mudah mengalami kejenuhan, sehingga rangsangan untuk bersungguh- sungguh dalam melakukan latihan akan berpengaruh terhadap peningkatan kemampuan akurasi passing. Peneliti di dalam latihan ini membuat beberapa variasi latihan untuk latihan 3 cone wall passing.

\section{Pengaruh Latihan " $V$ " roll to gated pass Terhadap Akurasi Passing}

Berdasarkan hasil penelitian menunjukkan bahwa ada pengaruh yang signifikan latihan " $V$ " roll to gated pass terhadap akurasi passing pemain SSB Neo Selaparang KU 12 tahun, dengan kenaikan persentase sebesar $36,81 \%$. Latihan " $V$ " roll to gated pass, latihan ini hampir mempunyai kemiripan dengan bentuk latihan 3 cone wall passing sama-sama menggunakan 3 buah cone yang di susun membentuk huruf "V" dengan jarak $40 \mathrm{~cm}$ per cone dan 10-20 meter jarak 
cone untuk target passing di depannya. Dengan jarak 10-20 meter untuk anak usia 12 tahun tidak mengalami kesulitan untuk melakukan passing yang tepat. Passing yang dilakukan secara bergantian dengan beberapa pasangan. Latihan ini hampir sama dengan latihan passing lurus berhadapan, hanya saja berbeda dalam melakukan arah passing dan juga kecermatan dalam melakukan arah passing yang selalu bergerak ke arah serong kanan dan kiri dengan menarik menggunakan alat kaki terhadap bola lalu ditarik ke dalam dan mendorong bola menggunakan kaki bagian dalam ke arah serong kiri, dalam latihan passing variasi ini posisi pemain berada di belakang cone bentuk "V" dan pemain di depan 2 cone yang dijadikan target yang berjarak 10-20 meter. Kemudian dalam melakukan passing dengan bergantian sesuai pasangannya. Latihan ini dapat untuk meningkatkan kemampuan dalam ketepatan passing. Dalam latihan ini peneliti membuat beberapa bentuk variasi latihan " $V$ " roll to gated pass agar para pemain tidak mengalami kejenuhan dalam berlatih.

Latihan 3 cone wall passing adalah bentuk latihan yang tersusun dari 3 cone yang dijajarkan dan di depannya ada titik sasaran berupa dinding namun peneliti mengganti dinding tersebut dengan titik sasaran menggunakan cone di karenakan keterbatasan fasilitas. Dan divariasikan dengan di depan 3 cone dengan jarak 10-20 meter terdapat target gawang kecil yang tersusun oleh 2 cone. Kemudian pemain men-dribbling ke kanan dan ke kiri lalu passing ke target.Latihan ini dilakukan untuk meningkatkan kemampuan ketepatan passing sekaligus untuk meningkatkan kemampuan kontrol bola dari pemain yang melakukannya. Latihan kedua adalah " $V$ " roll to gated pass, latihan ini hampir mempunyai kemiripan dengan bentuk latihan 3 cone wall passing sama-sama menggunakan 3 buah cone yang bentuk asli dari model latihan ini di susun membentuk huruf "V". dengan jarak $40 \mathrm{~cm}$ per cone dan 10-20 meter jarak cone untuk target passing di depannya. Passing yang dilakukan secara bergantian dengan beberapa pasangan. Latihan ini hampir sama dengan latihan passing lurus berhadapan,hanya saja berbeda dalam melakukan arah passing.

Kecermatan dalam melakukan arah passing yang selalu bergerak ke arah serong kanan dan kiri dengan menarik menggunakan alat kaki terhadap bola lalu ditarik ke dalam dan mendorong bola menggunakan kaki bagian dalam ke arah serong kiri, dalam latihan " $V$ " roll to gated pass ini posisi pemain berada di belakang cone bentuk "V" dan pemain di depan 2 cone yang dijadikan target yang berjarak 10-20 meter. Kemudian dalam melakukan passing dengan bergantian sesuai pasangannya. Latihan ini dapat untuk meningkatkan kemampuan dalam ketepatan passing. Dalam latihan ini peneliti membuat beberapa bentuk variasi latihan " $V$ " roll to gated pass agar para pemain tidak mengalami kejenuhan dalam berlatih.

\section{KESIMPULAN}

Berdasarkan hasil analisis data penelitian dan pembahasan, maka diperoleh kesimpulan, sebagai berikut:

1. Ada pengaruh yang signifikan latihan 3 cone wall passing terhadap akurasi passing pemain SSB Neo Selaparang KU 12 tahun.

2. Ada pengaruh yang signifikan latihan " $V$ " roll to gated pass terhadap akurasi passing bawah pemain SSB Neo Selaparang KU 12 tahun, dengan kenaikan persentase sebesar.

\section{DAFTAR PUSTAKA}

Agus Salim. (2008). Buku Pintar Sepak Bola. Bandung: NUANSA.

Bompa, T. (1994). Theory and Methodology of Training. Kendal: Low Publishing Company. 
Chouril Umam. (2014). Pengaruh Latihan Wall Pass Terhadap Kemampuan Shooting Permainan Sepakbola Pada Pemain Penjaskesrek Putra Kelas A Angkatan 2014. Skripsi.FKIP UNILA Edwin Vasaloga. (2014). Pengaruh Latihan Shooting Dengan Kaki Punggung Bagian Dalam dan Kaki Punggung Terhadap Ketepatan Shooting di Akademi Sriwijaya FC. Skripsi.FIK UNY

Faruq Muhammad Muhyi. (2008). Meningkatkan Kebugaran Tubuh Melalui Permainan dan Olahraga Sepak Bola. Surabaya: Gramedia Widiasarana Indonesia.

Ismaryati. (2008). Tes \& Pengukuran Olahraga. Surakarta: Universitas Sebelas Maret Surakata.

Mielke, D. (2007). Dasar-Dasar Sepakbola. Bandung: Pakar Raya.

Rahmad Darmawan \& Ganesha. (2012). Jadi Juara dengan Sepak Bola Possesion. Jakarta: KickOff Media - RD Book

Sugiyono. (2011). Metode Penelitian Pendidikan (Pendekatan Kuantitatif, Kualitatif dan R\&D). Bandung: Alfabeta..

Yanuar, Arif Musrifin \& Andi Anshari Bausad, 2020. Analisis Unsur Kondisi Fisik Pemain Sepak Bola Mataram Soccer Akademi NTB. Jurnal Ilmiah Mandala Education, Vol. 6. No. 1. April 2020. p-ISSN: 2442-9511 e-ISSN: 2656-5862. 